\title{
PHRAGMÉN-LINDELÖF TYPE ALTERNATIVE RESULTS FOR THE STOKES FLOW EQUATION
}

\author{
YAN LIU AND CHANGHAO LIN
}

\begin{abstract}
In this paper,we derive estimates for weighted energy expression for the solution of the Stokes flow equation in a semi-infinite plane channel by means of a second order differential inequality.From the estimates, we establish Phragmén-Lindelöf alternative that the solutions either grow or decay exponentially.In the case of decay,we also show how to bound the total weighted energy.
\end{abstract}

Mathematics subject classification (2000): 35B40, 35K50, 35K45.

Key words and phrases: transient stokes flow equation, Phragmén-Lindelöf alternative, stream function, energy estimate.

\section{REFERENCES}

[1] K. A. Ames, L. E. PaYne, Decay estimates in steady pipe flow, SIAM, J. Math. Anal., 20, (1986), 789-815.

[2] K. A. Ames, L. E. Payne, P. W. Schaefer, Spatial decay estimates in time-dependent stokes flow, SIAM J. Math. Anal., 24, (1993), 1395-1413.

[3] B. A. BOLEY, The determination of temperature, stresses and deflection in two-dimensional thermoelastic problem, J. Aero. Sci, 23, (1956), 67-75.

[4] B. A. BoLeY, Upper bounds and Saint-Venant's principle for transient heat conduction, Quart Appl. Math., 18, (1960), 205-207.

[5] W. S. EDELSTEIN, A spatial decay estimates for the heat equation, Z. Angew. Math. Phys. (ZAMP), 20, (1969), 900-905.

[6] J. N. Flavin, On Knowles' version of Saint-Venant's principle in two-dimensional elastostatics, Arch. Rational Mech. Anal., 53, (1974), 366-375.

[7] J. N. FlaVin, R. J. KNops, Some convexity considerations for a two dimensional traction problem, Z Angew Math. Phys, (ZAMP), 39, (1988), 166-176.

[8] J. N. FlaVIn, R. J. KNOPS AND L. E. PAYNE, Asymptotic behaviour of solutions to semi-linear elliptic equation on the half cylinder, Z . Angew. Math. Phys. (ZAMP), 43, (1992), 405-421.

[9] C. O. HorgAn, L. T. WHEELER, Spatial decay estimates for the heat equation via the Maximum principle, Z. Angew. Math. Phys. (ZAMP), 27, (1976), 371-376.

[10] C. O. HoRgAn, J. K. KNOWLES, Recent developments concerning Saint-Venant's principle, in Advances in Applied Mechanics, I. Y. Wu and J. W. Hulchinson(eds) 23, (1983), Academic Press, San Diego. 179-264.

[11] C. O. Horgan, L. E. Payne AND L. T. WheEler, Spatial decay estimates in transient heat equation, Quart, Appl. Math., 42, (1984), 119-127.

[12] C. O. HoRGAN, Recent developments concerning Saint-Venant's principle:An update, Applied Mechanics Reviews, 42, (1989), 295-302.

[13] C. O. HoRgan, Decay estimates for the biharmonic equation with application to Saint-Venant's principle in plane elasticity and Stokes Flows, Quart. Appl. Math., 42, (1989), 147-157.

[14] C. O. Horgan, L. E. PaYne, Phragmen-Lindelöf type results for harmonic functions with nonlinear boundary conditions, Arch. Rational Mech. Anal., 122, (1993), 123-144. 
[15] C. O. Horgan, Recent development concerning Saint-Venant's principle: A second update, Appl. Mech. Reviews., 49, (1996), 101-111.

[16] J. K. KNowles, On the spatial decay of solutions of the heat equation, Z. Angew. Math. Phys., 22, (1971), 1050-1056.

[17] J. K. KNOWLES, An energy estimates for the biharmonic equation and its application to Saint-Venant's principle in plane elastostatics, Indian. J. Pure Appl. Math., 14, (1983), 791-805.

[18] C. LiN, Spatial decay estimates and energy bounds for the stokes flow equation, SAACM., 2, (1992), 249-264.

[19] C. LIN, L. E. PAYNE, A Phragmen-Lindelöf type results for second order quasilinear parabolic equation in $R^{2}$, Z. Angew Math. Phys, (ZAMP), 45, (1994), 294-311.

[20] C. LIN, L. E. PAYNE, Phragmen-Lindelöf alternative for a class of quasilinear second order parabolic problems, Diff, Integ. Equa., 8, (1995), 539-551.

[21] O. A. OlEINIK, G. A. Yosifian, The Saint-Venant's principle in the two-dimensional theory of elasticity and boundary problems for a biharmonic equation in unbounded domains, Siberian Math J, 19, (1978), $813-822$.

[22] O. A. OleiniK, G. A. Yosifian, On Saint-Venant's principle in plane elasticity theory, Soviet Math Dokl, 19, (1978), 364-368.

[23] L. E. PAYne, P. W. SchaEfer, Some Phragmen-Lindelöf type results for the biharmonic equation, Z. Angew Math. Phys, 45, (1994), 414-432.

[24] A. J. C. B, DE SAINT-VEnANT, Mémoire sur la flexion des prismes, J Math Pures Appl, 1, (ser. 2), (1856) 89-189.

[25] V. G. SigiLlito, On the spatial decay of solution of parabolic equation, Z Angew Math. Phys. (ZAMP), 21, (1970), 1078-1081.

[26] J. C. Song, Improved decay estimates in time dependent Stokes flow, J. Math. Anal. Appl., 288, (2003), 505-517. 